\title{
PENGGUNAAN ACTION CAMERA PADA SPHERICAL PHOTOGRAMMETRY UNTUK PEMODELAN TIGA DIMENSI
}

\author{
${ }^{1}$ Joko Hartadi, ${ }^{1}$ Taufiq Ihsanudin, ${ }^{1}$ Oktavia Dewi Alfiani, dan ${ }^{2}$ Dessy Apriyanti \\ ${ }^{1}$ Staf Pengajar Teknik Geomatika Fakultas Tenologi Mineral UPN “Veteran” Yogyakarta \\ ${ }^{2}$ Staf Pengajar Teknik Geodesi Fakultas Teknik Universitas Pakuan Bogor \\ e-mail: jokohartadi@upnyk.ac.id
}

\begin{abstract}
Abstrak. Penggunaan action camera untuk pengumpulan data dapat diterapkan untuk pengambilan data spherical photogrammetry. Data foto diambil dengan memposisikan kamera pada salah satu titik exposure. Titik ini menjadi sumbu rotasi kamera saat melakukan pengambilan foto dengan sudut pandang $360^{\circ}$. Overlap kamera panoramik dibuat vertikal untuk mendapatkan foto stereo fasad candi yang akan dibuat model tiga dimensinya. Pembuatan foto panorama memerlukan beberapa foto dengan membuat bagian dari foto yang saling bertampalan (overlap). Kelebihan foto ini ialah dengan sekali berdiri alat dapat meliput sudut pandang $360^{\circ}$ dalam arah horisontal dan $180^{\circ}$ dalam arah vertikal. Permukaan objek yang dimodelkan dapat direpresentasikan dalam bentuk mesh. Mesh (dalam komunitas komputer grafik) diperoleh dari penggabungan titik-titik yang menghubungan setiap fitur yang sama menjadi jaring segitiga atau biasa disebut sebagai triangular irregular network (TIN) dalam fotogrametri. Hasil akhir dari rekonstruksi objek adalah model 3D yang memiliki tekstur.
\end{abstract}

Kata Kunci: action camera; spherical photogrammetry; model 3D

\begin{abstract}
The use of action camera for data collection can be applied to spherical photogrammetry. 3D model data from the acquisition of action camera produces different models with the original form of the object. Photo data was taken by positioning the camera at one exposure point. This point was used as the camera's rotational axis when shooting at $360^{\circ}$ viewing angle. Overlap panoramic camera was made be vertical to get stereo photo of the temple facade which will be made 3D model. The generation of panoramic photo needs some photos which generate a part from overlapping area. The benefit of this photo is could 360 degree point of view horizontally and 180 degree vertically by only using one stand instrument. The surface of the object can be represented in mesh form. Mesh (in the computer graph community) was derived from integration of the point which connected with the same features into a triangular net, it known as Triangular Irregular Network (TIN) in photogrammetry. Final result of object reconstruction is $3 D$ model which having texture.
\end{abstract}

Keywords: action camera; spherical photogrammetry; 3D mode

\section{PENDAHULUAN}

Perkembangan teknologi saat ini, penggunaan action camera untuk pengumpulan data geospasial menjadi sesuatu yang populer. Action Camera atau Kamera Aksi adalah perangkat kamera yang dirancang dengan tombol dan fungsi yang simpel untuk mengabadikan berbagai momen. Berbagai jenis action camera seperti GoPro Hero dan Xiaomi Yi telah beredar dipasaran dengan harga yang terjangkau. Pada dasarnya action camera yang merupakan kamera digital dengan karakteristik ringan, berdimensi kecil, tahan air, dan field of view (FOV) yang lebar dikembangkan untuk kegiatan olahraga maupun fotografi dasar laut. Berdasarkan karakteristiknya, penggunaan action camera mulai meluas untuk kegiatan pengumpulan data menggunakan Unmanned Aerial Vehicle (UAV), mobile mapping system, maupun kegiatan fotogrametri lainnya (Teo, 2015). Gambar dibawah ini adalah contoh kamera action camera tipe Xiaomi Yi.

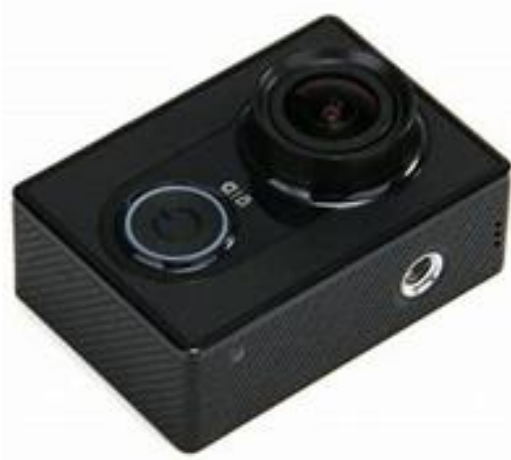

Gambar 1. Action camera Xiaomi Yi 
Secara umum, action camera memudahkan pengguna untuk melakukan pengambilan data geospasial. Data geospasial yang dimaksud dapat berupa data model tiga dimensi. Penggunaan action camera dalam pengambilan data ini memiliki kelebihan yaitu bersifat fleksibel dan membutuhkan biaya minimal (Cruz dkk, 2015). Penggunaan action camera dalam pengambilan data dapat dilakukan dengan metode fotogrametri jarak dekat. Metode ini memungkinkan pengguna untuk mengambil data dalam rentang jarak kurang dari 300 meter (Wolf dkk, 2014).

Salah satu aplikasi fotogrametri jarak dekat metode teristris adalah spherical photogrammetry atau foto panorama. Pembuatan foto panorama memerlukan beberapa foto yang diambil dengan membuat beberapa bagian dari foto saling bertampalan (overlap). Pertampalan tiap-tiap foto dengan tujuan foto memiliki sudut pandang yang lebih luas dibandingkan dengan foto awal. Kelebihan foto ini dengan sekali berdiri alat dapat memiliki sudut pandang $360^{\circ}$ dalam arah horisontal dan $180^{\circ}$ dalam arah vertikal. Foto panorama memberikan lebih banyak informasi spasial dibandingkan sebuah foto tunggal pada umumnya. Foto panorama mendapatkan pandangan lebar dari satu kali berdiri alat. Sedangkan kekurangan foto panorama ialah efek pergeseran kamera, objek terlihat cembung, perbedaan nilai kecerahan foto, dan kesalahan distorsi foto.

Tiap-tiap action camera memiliki perbedaan dari segi spesifikasi seperti sensor kamera dan fokus kamera. Lensa yang digunakan berbentuk wide lens sehingga tingkat distorsi yang dihasilkan jauh lebih besar (Balleti dkk, 2014). Hal tersebut mengakibatkan hasil perekaman suatu objek berbeda signifikan dibandingkan dengan bentuk aslinya. Untuk itu perlu dilakukan koreksi distorsi pada hasil perekaman objek. Koreksi distorsi dibutuhkan agar didapatkan data foto yang akurat. Untuk melakukan koreksi distorsi digunakan parameter-parameter geometrik lensa yang dihasilkan dari proses kalibrasi kamera.

Alat yang digunakan dalam penelitian ini adalah Xiaomi Yi. Tujuan dari penelitian ini adalah pemanfaatan action camera pada perekaman spherical photogrammetry untuk pembuatan model tiga dimensi. Pengumpulan data pemotretan dilakukan di Gerbang Candi Ratu Boko Dukuh Dawung, Desa Bokoharjo dan Dukuh Sumberwatu,
Desa Sambireja, Kecamatan Prambanan, Kabupaten Sleman, Yogyakarta.

\section{METODOLOGI}

Bahan yang digunakan dalam penelitian ini adalah data pemotretan spherical photogrammetry menggunakan Action Camera. Data foto diambil dengan memposisikan kamera pada salah satu titik exposure. Titik ini menjadi sumbu rotasi kamera saat melakukan pengambilan foto dengan sudut pandang $360^{\circ}$. Overlap kamera panoramik dibuat vertikal untuk mendapatkan foto stereo fasad candi yang akan dibuat model tiga dimensinya. Konfigurasi pengambilan gambar metode spherical photogrammtry dapat dilihat pada gambar 2 .

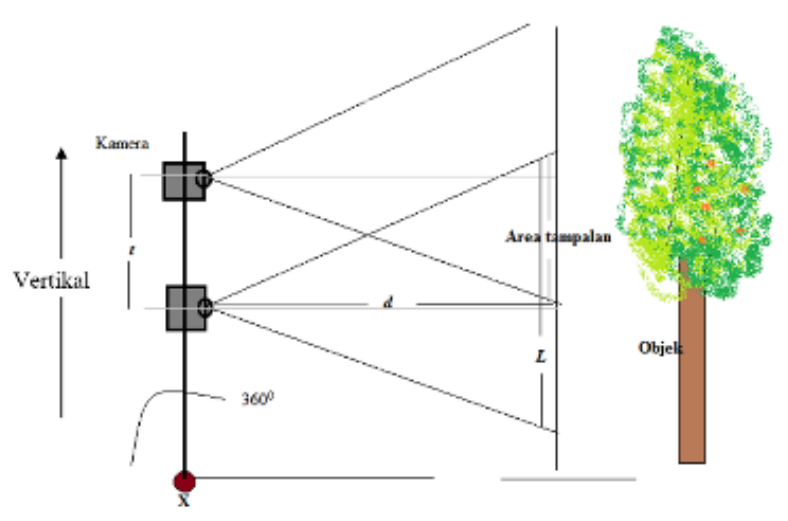

Gambar 2. Konfigurasi kamera pengambilan objek

Cruz dkk (2015) melakukan penelitian yang bertujuan mengembangkan sistem fotogrametri untuk pemodelan tiga dimensi agar hasil pemodelan menggunakan action camera (GoPro) memiliki ketelitian yang hampir setara dengan data model tiga dimensi menggunakan survei terestris. Konsep utama yang digunakan adalah konsep sterioskop dengan memanfaatkan dua eksposur yang simultan untuk memproses data dari dua kamera yang menangkap gambar secara bersamaan.

Para peneliti terus mengembangkan metode spherical photogrammetry, baik dalam unsur ketelitian, kemanfaatan, produk, dan alur kerja akuisisi datanya di lapangan. Spherical photogrammetry menunjukkan metode yang efisien dalam menciptakan produk dokumentasi arsitektur (Alsadik, 2014), dan salah satu produknya adalah citra panorama. Dokumentasi arsitektur 
berupa citra panorama ini dapat diperoleh dengan cepat, biaya survey yang rendah, dan memiliki ketelitian data yang baik (Fangi, 2015).

Optimasi pembuatan foto panorama untuk mengurangi distorsi pernah diteliti oleh Pramulyo (2016). Data citra panorama yang telah direkam tahap selanjutnya ialah dilakukan stitching. Proses stitching citra panorama adalah teknik menggabungkan beberapa citra menjadi citra dengan sudut pandang yang lebih luas, resolusi lebih tinggi, dan cepat, namun memiliki distorsi yang besar. Distorsi ini perlu dikoreksi, yaitu dengan melakukan kalibrasi kamera sebagai alur kerja tambahan pada spherical photogrammetry. Hasilnya menunjukkan bahwa kalibrasi kamera dapat mengkoreksi distorsi, mengoptimasi kualitas data citra panorama, dan meningkatkan efisiensi alur kerja spherical photogrammetry sebagai terobosan bagi teknologi dokumentasi arsitektur yang lebih baik.

\section{HASIL DAN PEMBAHASAN}

\section{Hasil Kablibrasi Kamera}

Kalibrasi kamera digunakan untuk menentukan parameter orientasi dalam atau internal orientation parameter (IOP). Balletti dkk (2015) melakukan penelitian terkait dengan berbagai macam proses kalibrasi terhadap action camera menggunakan beberapa perangkat lunak untuk keperluan fotogrametri. Hasil penelitian ini menyebutkan bahwa kalibrasi kamera dapat mengurangi distorsi yang terjadi dan meningkatkan ketelitian hasil pemodelan.

Kamera yang telah dikalibrasi memiliki parameter panjang fokus (f), principle point (xo, yo), dan distorsi lensa (K1, K2, K3, P1, P2) telah diketahui. Hasil kalibrasi kamera 1 dan kamera 2 untuk pemotretan spherical photogrammetry dilihat pada tabel 1 .

Tabel 1. Hasil kalibrasi kamera.

\begin{tabular}{lll} 
& \multicolumn{2}{c}{ Tabel 1. Hasil kalibrasi kamera. } \\
\hline Parameter & \multicolumn{1}{c}{ Kamera 1 } & Kamera 2 \\
\cline { 2 - 3 } f & (piksel) & (piksel) \\
X0 & $1.898,072$ & $2.097,146$ \\
Y0 & 471,936 & $-152,670$ \\
k1 & 26,184 & $-16,081$ \\
k2 & 1,388 & 0,547 \\
k3 & $-1,118$ & -0.761 \\
p1 & 1,489 & 1,961 \\
p2 & 0,286 & $-0,055$ \\
\hline
\end{tabular}

Nilai kalibrasi tersebut merupakan besaran kesalahan akibat tidak sempurnanya lensa kamera, maka saat proses foto diperlukan nilai parameter untuk meminimalisir distorsi foto. Panjang fokus (f) adalah jarak tegak lurus antara titik pusat lensa (titik fokus) dengan bidang proyeksi kamera (CCD/CMOS) dalam kamera. Principle point (xo, yo) atau titik pusat foto merupakan titik utama hasil proyeksi tegak lurus titik pusat prespektif (titik pusat proyeksi) pada bidang foto. Titik ini merupakan titik utama pada sistem koordinat foto. Distorsi lensa (K1, K2, K3, P1, P2) adalah kesalahan pada lensa yang menyebabkan hasil foto objek tidak mencerminkan objek sebenarnya di lapangan. Distorsi menyebabkan tidak tepatnya proyeksi dari pusat prespektif lensa terhadap bidang foto, sehingga letak proyeksinya tidak tepat pada sistem koordinat foto.

\section{Pendefinisian Stasiun}

Stasiun digunakan untuk mengelompokkan foto mana saja yang akan dibuat panoramanya. Satu stasiun terdiri atas beberapa foto yang memiliki tampalan, yaitu foto yang diambil dari satu kamera. Pembuatan folder foto dari masingmasing kamera dengan tujuan pengelompokan foto berdasarkan dengan station posisi kamera pada satu sumbu vertikal.

\section{REKONSTRUKSI OBJEK}

Tahap kedua adalah stitching photos yang digunakan untuk mengekstraksi titik-titik yang sama dari setiap foto. Titik-titik tersebut memungkinkan setiap fitur digabungkan berdasarkan kesamaan derajat keabuan piksel pada setiap fitur. Setiap stasiun menghasilkan satu buah foto panorama $360^{\circ}$ yang diproses secara langsung dari semua foto untuk menghasilkan stereo panorama $360^{\circ}$. Gambar 3 adalah tampilan dari titik-titik ikat yang dihasilkan saat proses penggabungan foto-foto membentuk stereo panorama. 


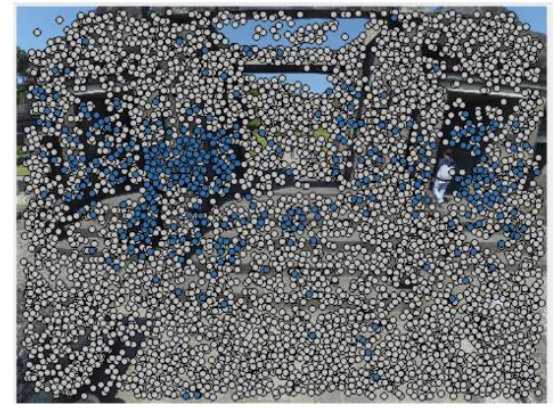

Gambar 3.a. titik-titik yang sama dari foto 1.

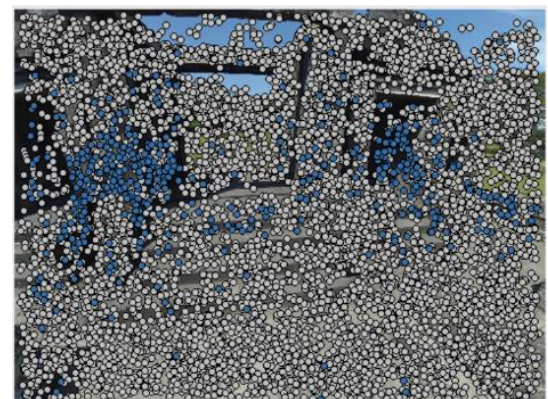

Gambar 3.b. titik-titik yang sama dari foto 2 .

Titik-titik pada objek dibentuk berdasarkan kesamaan derajat keabuan setiap fitur didalamnya. Titik-titik dengan kesamaan derajat keabuan dideteksi secara otomatis dan dianggap sebagai fitur yang sama. Hal ini menyebabkan beberapa fitur dengan kondisi yang serupa (homogen) yaitu fitur dengan nilai derajat keabuan yang sama dan fitur dengan kondisi tekstur yang halus dapat mengalami kesalahan dalam pendefinisiannya. Fitur yang seharusnya berbeda didefinisikan sebagai satu kelas yang sama. Titik-titik tersebut saling mengikat satu sama lain sehingga dapat terbentuk foto stereo panorama.

Penelitian ini menggunakan beberapa buah foto dari dua stasiun yang berbeda. Gambar 4 tersebut merupakan stasiun pemotretan dengan konfigurasi kamera secara vertikal. Konfigurasi kamera ini menghasilkan foto panorama yang bertampalan atas bawah dan menghasilkan sebuah foto stereo panorama.

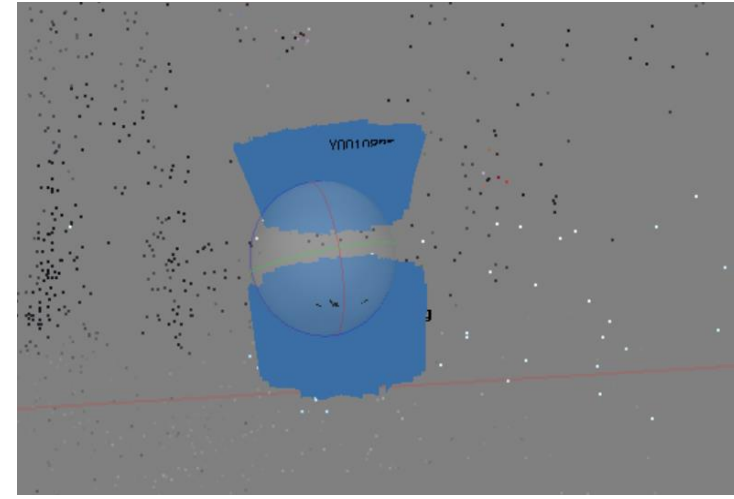

Gambar 4. Hasil stereo vertikal foto panoramik

Proses selanjutnya adalah pembentukan dense point cloud. Dense point cloud merupakan interpolasi dari titik ikat hasil image stitching, sehingga titik-titik yang dihasilkan jauh lebih rapat dan mampu menggambarkan objek lebih jelas. Dense point cloud telah memiliki koordinat tanah sesuai dengan koordinat yang didefinisikan sebelumnya. Hasil dari dense point cloud ditampilkan dalam gambar 5 .

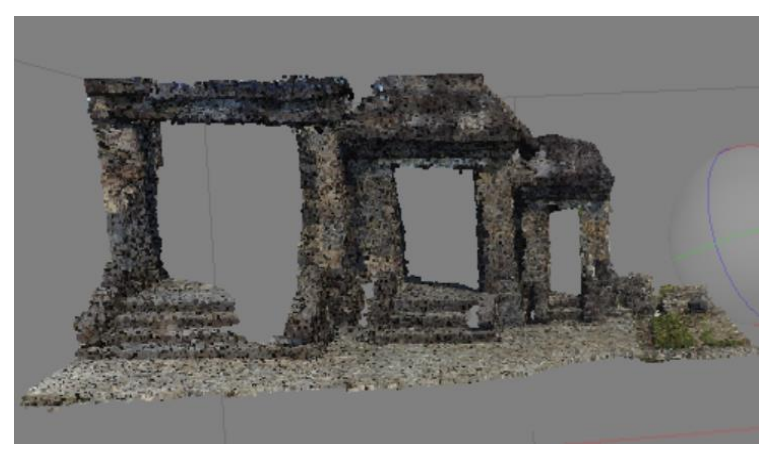

Gambar 5. Hasil dense point cloud

Dense point cloud yang telah terbentuk dihubungkan satu sama lain membentuk jaring segitiga atau triangular irregular network (TIN). Proses ini disebut sebagai proses pembuatan mesh atau model geometri. Metode yang digunakan dalam pembuatan mesh adalah metode arbitrary. Metode ini merupakan metode pembentukan geometri permukaan untuk berbagai macam objek yang diakuisisi dari jarak dekat, misalnya candi, dan bangunan. 


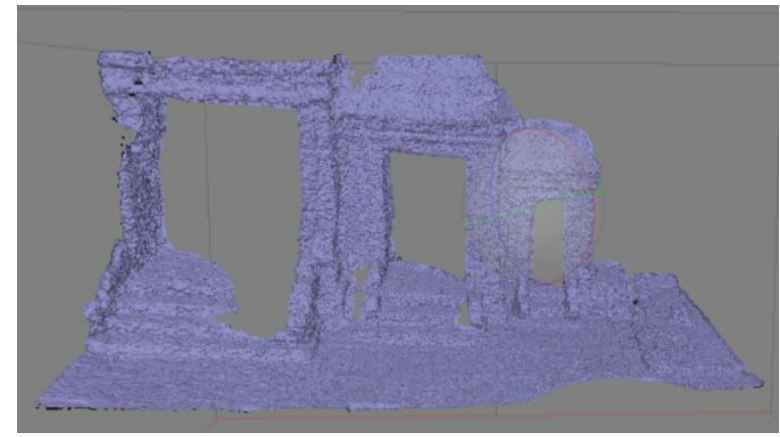

Gambar 6. Hasil pembentukan mesh

Pembuatan model 3D dilanjutkan ke tahap pemberian tekstur pada permukaan objek. Proses texturing ini bertujuan agar model 3D yang dihasilkan memiliki kenampakan yang mirip dengan kondisi di lapangan. Hal tersebut dilakukan dengan menampalkan sebuah foto, sebagian foto, atau keseluruhan foto di atas permukaan objek. Konsep dasar pembentukan tekstur ini yaitu mengkombinasikan nilai piksel dari berbagai foto dengan fitur yang sama. Untuk menghasilkan tekstur yang baik, beberapa metode dapat diterapkan sesuai dengan kebutuhan. Hasil preses tekstur model 3D dapat dilihat pada gambar III.10.

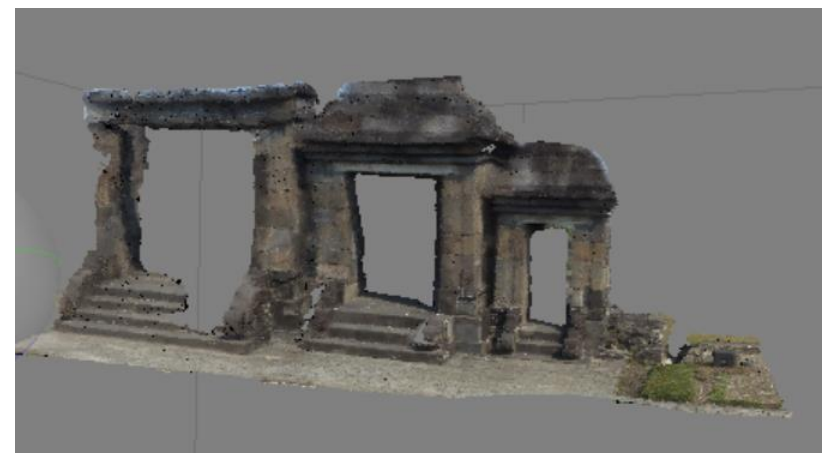

Gambar 7. hasil pembuatan tekstur model 3D spherical photogrammetry

Pemotretan sperichal Photogrammetry menghasilkan foto fasad candi disetiap sisi-sisinya. Hasil stitching menunjukkan konfigurasi kedua kamera secara vertikal dan membentuk sudut pandang $360^{\circ}$. Hasil akhir dari rekonstruksi objek adalah model 3D yang telah memiliki tekstur. Model 3D yang dihasilkan dari spherical photogrammetry merupakan dalam sistem koordinat lokal. Hasil pemodelan tiga dimensi candi ratu boko dapat dilihat pada gambar berikut.

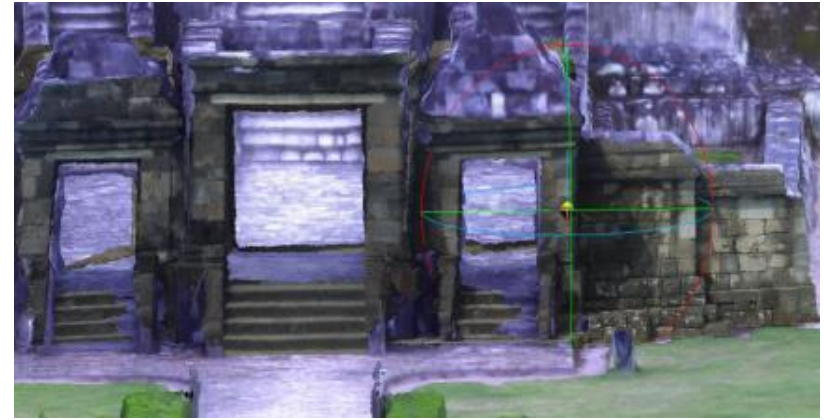

Gambar 8. Hasil model 3D Candi Ratu Boko.

\section{PENUTUP}

\section{Simpulan dan Saran}

Simpulan dalam penelitian ini adalah action camera dapat digunakan untuk pemotretan fotogrametri jarak dekat metode spherichal photogrammetry. Saat pemrosesan foto hasil perekaman menggunakan action camera perlu dilakukan kalibrasi agar dapat meminimalisir distorsi kamera.

Pemotretan objek sebaiknya dilakukan dengan memperbanyak stasiun pemotretan agar semakin detil objek yang diperoleh. Pemotretan dalam tempo waktu yang cepat untuk menghindari perubahan cuaca. Perubahan cuaca mengakibatkan tingkat kecerahan foto berbeda-beda sehingga berpengaruh saat proses image matching.

\section{Ucapan Terima Kasih}

Penulis mengucapkan terimakasih kepada Balai Besar Cagar Budaya Kawasan Wisata Candi Ratu Boko Yogyakarta yang telah memberikan izin untuk lokasi penelitian.

\section{DAFTAR PUSTAKA}

Alsadik, B. S. A. (2014). Guided Close Range Photogrammetry for 3D Modelling of Cultural Heritage Sites. Netherlands: ITC Printing Department.

Balletti, C., Guerra, F., Tsioukas, V. and Vernier, P., (2015). "Calibration of Action Camera for Photogrammetric Purposes", Sensors, 14: 1747117490

Cruz, D., Patricia Kristen.,Magtalas, M. S. Lyle., Principe, Jeark., (2015). "3D Model Generation Using Photogrammetric Analysis of Paired GoProTM Video", Philippines.

Fangi, G. (2015). Towards an Easier Orientation for Spherical Photogrammetry. The International Archives of the Photogrammetry, Remote Sensing 
and Spatial Information Sciences, Volume XL-5/W4, pp. 279-283.

Pramulyo, H. (2016). Towards Better 3d Model Accuracy With Spherical Photogrammetry. Thesis Department of Geodesy and Geomatics Engineering ITB, Bandung.

Teo, Tee-Ann., (2015). "Video-based Point Cloud Generation Using Multiple Action Camera", Taiwan.

Wolf, Paul R,. Dewitt, Bon A., Wilkinson, Benjamin E., (2014). Element of Photogrammetry with Applications in GIS, $4^{\text {th }}$ edition, McGraw-Hill Book Company. ISBN: 978-0-07-176111-6. 